\title{
Editorial: Cannabidiol Treatment in Neurotherapeutic Interventions
}

\author{
Gustavo Gonzalez-Cuevas ${ }^{1 *}$, Maria S Garcia-Gutierrez ${ }^{2}$, Francisco Navarrete ${ }^{2}$, \\ Giordano de Guglielmo ${ }^{3}$ and Jorge Manzanares ${ }^{2}$
}

${ }^{1}$ Department of Clinical Psychopharmacology, College of Pharmacy, Idaho State University, Meridian, ID, United States, ${ }^{2}$ Instituto de Neurociencias Universidad Miguel Hernandez-CSIC, San Juan de Alicante, Spain, ${ }^{3}$ University of California, San Diego, San Diego, CA, United States

Keywords: cannabidiol, neurotherapeutic, treatment, CBD-cannabidiol, neuropsychiatric disorders (NPD)

\section{Editorial on the Research Topic}

\section{Cannabidiol Treatment in Neurotherapeutic Interventions}

Cannabidiol, usually referred to as $\mathrm{CBD}$, is the second most abundant active ingredient in cannabis, one of the oldest medicinal plants in the world (Zuardi, 2006). Although CBD was first extracted from cannabis in 1940 (Adams et al., 1940), its chemical structure was not fully characterized until 1963 (Mechoulam and Shvo, 1963). In terms of its pharmacokinetic profile, CBD is highly lipophilic, have poor oral bioavailability (as low as 6\%), and is well tolerated by humans with no signs of toxicity or serious side effects and drug interactions (Millar et al., 2018; Huestis et al., 2019). Pharmacodynamically, CBD acts on over 65 molecular targets, including transient receptor potential vanilloid (TRPV) channels, serotonin (5$\mathrm{HT}_{1 \mathrm{~A}}$ ) receptors, and cannabinoid-related receptors such as $\mathrm{G}$ protein-coupled receptor 55 (GPR55).

\section{OPEN ACCESS}

Edited and reviewed by: Nicholas M Barnes, University of Birmingham, United Kingdom

*Correspondence: Gustavo Gonzalez-Cuevas gonzgust@isu.edu

Specialty section:

This article was submitted to Neuropharmacology,

a section of the journal

Frontiers in Pharmacology

Received: 02 August 2021 Accepted: 14 September 2021 Published: 18 October 2021

Citation:

Gonzalez-Cuevas $G$ Garcia-Gutierrez MS, Navarrete F, de Guglielmo $G$ and Manzanares J (2021) Editorial: Cannabidiol Treatment

in Neurotherapeutic Interventions.

Front. Pharmacol. 12:752292.

doi: 10.3389/fphar.2021.752292
Interestingly, the actions of $\mathrm{CBD}$ on the two main endocannabinoid receptors are limited by its low affinity. At higher doses, it functions as a negative allosteric modulator for $\mathrm{CB}_{1}$ receptors and an inverse agonist for $\mathrm{CB}_{2}$ receptors. Indirectly, $\mathrm{CBD}$ also activates $\mathrm{CB}_{1}$ receptors by inhibiting fatty acid amide hydrolase $(\mathrm{FAAH})$, the enzyme that degrades anandamide (AEA), the endogenous ligand for $\mathrm{CB}_{1}$ receptors (Britch et al., 2021). It is important to note that, unlike tetrahydrocannabinol (i.e., THC, the main psychoactive chemical in cannabis), CBD is non-addictive (Viudez-Martinez et al., 2019), which makes it an exceptional alternative to THC-derivative cannabinoid drugs.

Touted as a cure-all for many health conditions and disorders (e.g., anxiety, depression, schizophrenia, PTSD), CBD has become increasingly ubiquitous in the marketplace (Brown and Winterstein, 2019). Spurred by the increasing legality of the medical use of the Cannabis sativa plant, a number of medical benefits of CBD have been reported. In the U.S. specifically, CBD (Epidiolex ${ }^{\circledR}$ ) is currently marketed for the treatment of Dravet and Lennox-Gastaut syndromes, pediatric epilepsies resistant to anticonvulsants, as well as for spasticity in multiple sclerosis (Sativex ${ }^{\circledR}$, THC:CBD). Emerging evidence from basic and clinical research suggests a relevant role for CBD in treating a variety of neuropsychiatric disorders, including schizophrenia (Osborne et al., 2017), mood disorders (Pinto et al., 2020), PTSD (Bitencourt and Takahashi, 2018), and drug addiction (Gonzalez-Cuevas et al., 2018; Viudez-Martinez et al., 2018), among others. However, very little is still known regarding the precise neurobiological mechanisms, pharmacokinetics, drug interactions, and clinical consequences of CBD treatment in many of these psychiatric conditions.

Despite the current CBD "boom" in commercially available products, often at the edge of the law (Mead, 2017), it remains to be investigated if CBD is an effective medical treatment for a wide range of neuropsychiatric conditions. In this special issue "Cannabidiol Treatment in Neurotherapeutic Interventions," we present a series of reviews and research papers written by leading authors in the field of neuropsychopharmacology, providing a deep overview and analysis of scientifically sound evidence 
that evaluates the use of CBD alone or associated with another drug as a new therapeutic tool for the treatment of mental disorders.

Regarding the role of CBD in epilepsy, Dubois et al. evaluate a volumetric absorptive microsampling (VAMS) method combined with LC-MS/MS (liquid chromatography coupled to tandem mass spectrometry) that allows quantification of CBD blood levels, offering valuable support for personalized therapy in refractory epilepsy, and Contin et al. report the first clinical pharmacokinetic study in patients with Dravet and Lennox-Gastaut syndrome. Furthermore, Raucci et al. demonstrate the role of the endocannabinoid system in epileptogenesis and alert about the need to conduct doubleblinded placebo-controlled trials about $\mathrm{CBD}$ efficacy and safety. Exploring the role of CBD in Alzheimer's disease, Coles et al. find supporting evidence of CBD treatment potential for ameliorating cognitive impairments associated with this disease. Related to the potential treatment of schizophrenia with $\mathrm{CBD}$, Leweke et al. show that $\mathrm{CBD}$ improves neurocognitive functioning in schizophrenics and Loss et al. point out to the CBD's beneficial potential for the neurodevelopmental disorders of schizophrenia as well as autism spectrum disorders. For CBD research on mood disorders, Gasparyan et al. report that the combination of $\mathrm{CBD}$ and sertraline attenuates PTSD-related behavioral disturbances in mice, while normalizing gene expression alterations. Finally, a number of articles review the potential treatment of CBD for neuropsychiatric interventions: Navarrete et al. summarize the key involvement of $\mathrm{CBD}$ in the therapeutic intervention for Substance Use Disorders,

\section{REFERENCES}

Adams, R., Hunt, M., and Clark, J. H. (1940). Structure of Cannabidiol, a Product Isolated from the Marihuana Extract of Minnesota Wild Hemp. I. J. Am. Chem. Soc. 62, 196-200. doi:10.1021/ja01858a058

Bitencourt, R. M., and Takahashi, R. N. (2018). Cannabidiol as a Therapeutic Alternative for post-traumatic Stress Disorder: from Bench Research to Confirmation in Human Trials. Front. Neurosci. 12, 502. doi:10.3389/ fnins.2018.00502

Britch, S. C., Babalonis, S., and Walsh, S. L. (2021). Cannabidiol: Pharmacology and Therapeutic Targets. Psychopharmacology (Berl) 238 (1), 9-28. doi:10.1007/ s00213-020-05712-8

Brown, J. D., and Winterstein, A. G. (2019). Potential Adverse Drug Events and Drug-Drug Interactions with Medical and Consumer Cannabidiol (CBD) Use. J. Clin. Med. 8 (7), 989. doi:10.3390/jcm8070989

Gonzalez-Cuevas, G., Martin-Fardon, R., Kerr, T. M., Stouffer, D. G., Parsons, L. H., Hammell, D. C., et al. (2018). Unique Treatment Potential of Cannabidiol for the Prevention of Relapse to Drug Use: Preclinical Proof of Principle. Neuropsychopharmacology 43 (10), 2036-2045. doi:10.1038/s41386-018-0050-8

Huestis, M. A., Solimini, R., Pichini, S., Pacifici, R., Carlier, J., and Busardò, F. P. (2019). Cannabidiol Adverse Effects and Toxicity. Curr. Neuropharmacol 17 (10), 974-989. doi:10.2174/1570159X17666190603171901

Insel, T. R. (2012). Next-generation Treatments for Mental Disorders. Sci. Transl Med. 4 (155), 155ps19. doi:10.1126/scitranslmed.3004873

Lake, J., and Turner, M. S. (2017). Urgent Need for Improved Mental Health Care and a More Collaborative Model of Care. Perm J. 21, 17-024. doi:10.7812/TPP/17-024

Mead, A. (2017). The Legal Status of Cannabis (Marijuana) and Cannabidiol (CBD) under U.S. Law. Epilepsy Behav. 70 (Pt B), 288-291. doi:10.1016/ j.yebeh.2016.11.021

Mechoulam, R., and Shvo, Y. (1963). Hashish. I. The Structure of Cannabidiol. Tetrahedron 19, 2073-2078. doi:10.1016/0040-4020(63)85022-X

Millar, S. A., Stone, N. L., Yates, A. S., and O'Sullivan, S. E. (2018). A Systematic Review on the Pharmacokinetics of Cannabidiol in Humans. Front. Pharmacol. 9, 1365. doi:10.3389/fphar.2018.01365
Batalla et al. provide an overview of the neuroimaging studies in which $\mathrm{CBD}$ modulate functional networks relevant for psychiatric disorders, Patricio et al. focus on the neurobiological mechanisms of the CBD actions in the treatment of Parkinson's disease and L-dopainduced dyskinesias, Scarante et al. explore the contribution of glial cells to CBD effects in neuropsychiatric disorders, and MartinezOrgado et al. assess the neuroprotective effects of CBD against Hypoxic-Ischemic Brain Injury (HIBI) in preclinical studies.

Neuropsychiatric illness, currently accounting a third of adult disability worldwide (Lake and Turner, 2017), will become the next major global health challenge unless new neurotherapeutics can be proven to provide clinical benefit (Insel, 2012). These are exciting times for research on CBD since it has demonstrated a wide range of promising therapeutic applications in preclinical studies, including the treatment of neuropsychiatric disorders. The current findings make this drug an attractive candidate for future clinical use and warrant further investigations. Only time, coupled with methodologically rigorous clinical trials, shall reveal the extent $\mathrm{CBD}$ interventions contribute to winning the fight against the mental pandemic of the 21 st century.

\section{AUTHOR CONTRIBUTIONS}

All authors listed have made a substantial, direct, and intellectual contribution to the work and approved it for publication.

Osborne, A. L., Solowij, N., and Weston-Green, K. (2017). A Systematic Review of the Effect of Cannabidiol on Cognitive Function: Relevance to Schizophrenia. Neurosci. Biobehav Rev. 72, 310-324. doi:10.1016/j.neubiorev.2016.11.012

Pinto, J. V., Saraf, G., Frysch, C., Vigo, D., Keramatian, K., Chakrabarty, T., et al. (2020). Cannabidiol as a Treatment for Mood Disorders: A Systematic Review: Le cannabidiol comme traitement des troubles de l'humeur: une revue systématique. Can. J. Psychiatry 65 (4), 213-227. doi:10.1177/0706743719895195

Viudez-Martínez, A., García-Gutiérrez, M. S., Medrano-Relinque, J., Navarrón, C. M., Navarrete, F., and Manzanares, J. (2019). Cannabidiol Does Not Display Drug Abuse Potential in Mice Behavior. Acta Pharmacol. Sin 40 (3), 358-364. doi:10.1038/s41401-018-0032-8

Viudez-Martínez, A., García-Gutiérrez, M. S., Navarrón, C. M., Morales-Calero, M. I., Navarrete, F., Torres-Suárez, A. I., et al. (2018). Cannabidiol Reduces Ethanol Consumption, Motivation and Relapse in Mice. Addict. Biol. 23 (1), 154-164. doi:10.1111/adb.12495

Zuardi, A. W. (2006). History of Cannabis as a Medicine: a Review. Braz. J. Psychiatry 28 (2), 153-157. doi:10.1590/s1516-44462006000200015

Conflict of Interest: The authors declare that the research was conducted in the absence of any commercial or financial relationships that could be construed as a potential conflict of interest.

Publisher's Note: All claims expressed in this article are solely those of the authors and do not necessarily represent those of their affiliated organizations, or those of the publisher, the editors and the reviewers. Any product that may be evaluated in this article, or claim that may be made by its manufacturer, is not guaranteed or endorsed by the publisher.

Copyright (c) 2021 Gonzalez-Cuevas, Garcia-Gutierrez, Navarrete, de Guglielmo and Manzanares. This is an open-access article distributed under the terms of the Creative Commons Attribution License (CC BY). The use, distribution or reproduction in other forums is permitted, provided the original author(s) and the copyright owner(s) are credited and that the original publication in this journal is cited, in accordance with accepted academic practice. No use, distribution or reproduction is permitted which does not comply with these terms. 